\title{
Livestock Trends and Farmers' Perceptions about their Impacts in Southern Zambia
}

\author{
Gelson Tembo (Corresponding author) \\ Department of Agricultural Economics \\ University of Zambia, P.O. Box 32379, Lusaka, Zambia \\ Tel: 260-974-779-572Ｅ-mail: tembogel@gmail.com \\ Evans Kapekele \\ Disaster Management and Mitigation Unit, Office of the Vice President, Lusaka, Zambia
}

Alice Tembo

Ministry of Mines, Energy and Water Development, P.O. Box 70318, Ndola, Zambia

Fusya Y. Goma

Department of Veterinary Services, Ministry of Agriculture and Livestock, P.O. Box 50060,

Lusaka, Zambia

Jairos Sambo

Department of Agricultural Economics, University of Zambia, Lusaka, Zambia

Received: February 12, 2014 Accepted: February 24, 2014

doi:10.5296/jas.v2i2.5397 URL: http://dx.doi.org/10.5296/jas.v2i2.5397

\begin{abstract}
This study uses data from a mixed-methods survey of livestock-rearing communities in three districts in the Southern Province of Zambia to understand trends in livestock numbers and smallholder farmers' perceptions about their impacts on livelihoods. The results show that
\end{abstract}


livestock numbers have generally declined due to disease outbreaks and distress selling of livestock, which are most prevalent during droughts. These have in turn led to a myriad of impacts, including: i) reduction of cultivated land area, ii) reduction of school-related expenditure, iii) households sliding on the poverty scale, and iv) reduction of expenditure on other household needs such as clothing. However, the extent to which these have been experienced varies by livestock system and poverty status of the household. Districts that rear less resilient livestock species, such as cattle, are more likely to perceive severe effects of livestock-related shocks, which tend to be worse when they are also poor.

Keywords: Livestock trends, Livelihood effects, Farmer perceptions, Zambia

\section{Introduction}

In many Southern Africa Development Community (SADC) countries, chronic vulnerability and poverty are entrenched and exacerbated by the ever-present risk of extreme climatic (drought and floods), economic and policy shocks. In Zambia, while these shocks affect all parts of the country, they are worse in the Southern Province. Comprising a 300,000 hectare valley, more than one million hectares of escarpment, and more than 5.9 million hectares of the Kafue flats, the province receives about $800 \mathrm{~mm}$ or less of rainfall annually. For example, in 2004/05, a drought year, Kazungula, Namwala and Sinazongwe received about 424 mm, 553 $\mathrm{mm}$ and $273 \mathrm{~mm}$ of rainfall, respectively (GRZ, 2005a; GRZ, 2005b; and GRZ, 2006).Such low levels of rainfall resulted in maize production losses in excess of 61 percent, compared to the previous season (GRZ, 2005a; GRZ, 2005b; and GRZ, 2006). In comparison, the highest rainfall region in Zambia receives about $1200 \mathrm{~mm}$ annually. The combined effect of the nature of the geographic landscape and the recurrence of droughts has been of concern to policy makers and development specialists.

Livestock is an important part of livelihood systems in Southern Province as they act as some form of insurance against shocks, such as these. In many cases, households respond to acute hunger through distress selling of livestock and using the proceeds to purchase other food items like grain. Unfortunately, while providing the much needed insurance over, livestock are themselves also affected by drought, floods and other such shocks. Incidences of diseases, for example, increase during drought as feed and water become scarce and large numbers of livestock are forced to cluster around small areas with feed and water. Thus, with the rapidly changing climatic conditions and the ever-increasing frequency of droughts, it is expected that the position of livestock in the hierarchy of options could be changing. This could be indicated, in part, by trends in numbers of livestock reared and farmers' perceptions about the associated impacts. This information, though important for policy and intervention design, is not readily available. .

Literature around the world suggests that livestock numbers respond to changes in climate and policies (Sherpa and Kayastha 2009; Gandiwa 2012; Rola et al., 2003). With these broad concepts emanating from the existing literature it is not yet clear how livestock populations are affected by risk management and weather shocks. This study presents trends in livestock numbers in Zambia and smallholder farmers' perceptions about their impact. Understanding of this topic could facilitate development of applicable policies and more appropriate and 
fruitful intervention strategies for smallholder farmers.

\section{Literature review}

Literature provides mixed views on livestock trends and their impacts, although there seems to be a general agreement of the factors that have lead to changes in livestock numbers. Commonly cited ones include economic growth and increased incomes (Steinfeld et al., 2006); increased demand arising from escalating population growth (Delgado et al. 1999); and diseases, inadequate and poor quality of pastures (Lubungu and Mukuka 2012). In developing countries, high disease prevalence and poor-quality feed are some of the major major factors linked to declining livestock numbers. Steinfeld et al. (2006) identifies structural differences between Asia and sub-Saharan Africa, which could, in part, account for the observed variations in livestock trends and impacts between the two regions. While demand and consumption of livestock products have been bolstered in Asia by increased incomes and economic growth, the same cannot be said of sub-Saharan Africa (Steinfeld et al. 2006). According to Gandiwa (2012) livestock populations have remained constant or have been declining in most developing countries.

While increasing livestock production is seen largely as a positive (see, for example, IFAD 2009), large livestock numbers do have their own downside. Some sections of the literature argue, for example, that increases in livestock populations could lead to global warming, land degradation, air and water pollution and loss of diversity (FAOSTAT 2006). Livestock have been responsible for 18 percent of green gas emissions, which is in fact a bigger share than the transport sector. The two opposing views imply that the question of impact of livestock trends is largely empirical, and further identify the need to decipher the answers through in-depth, interactive methods. Decision-makers' perceptions often arise from their complete understanding of their circumstances.

\section{Methodology}

\subsection{Collection of Data}

This study uses data from a mixed-methods survey of livestock-rearing communities in three districts of the Southern Province of Zambia, conducted during the 2006/2007 agricultural season. Southern Province has been experiencing a number of shocks like floods and droughts during much of the last few decades, often prompting food assistance to vulnerable populations. Of the country's ten provinces, Southern Province also stands out as one with the largest and most diversified smallholder livestock sector. The province is comprised of 11 districts, half of which are located in the low-rainfall (less than $800 \mathrm{~mm}$ annual rainfall) region, agro-ecological region (AER) I. This group can be further sub-divided into valley districts and those that are located in the sandy plateau in the south-western parts of the province. We call both these sub-categories of districts 'hot-spot' districts, owing to their high poverty and vulnerability levels. The other six districts belong to medium-rainfall (800-1,200 mm) region, AER II, here referred to as non-hotspot districts. 
One district was randomly selected from each of these strata-one from each of the hot-spot sub-categories (Sinazongwe from the valley stratum; and Kazungula from the sandy plateau stratum), and one from the non-hot-spot stratum (Namwala). Within each selected district and prior to primary data collection, all the agricultural camps or communities were stratified into four distinct groups based on relative productive potential (high or low) and market access (high or low). This was accomplished in close consultation with knowledgeable key informants such as government agricultural and veterinary staff. One community was randomly selected from each of the four community strata (Table 1).

Table 1. Variables used to stratify and select study communities and households, August 2006

\begin{tabular}{|c|c|c|c|c|}
\hline \multicolumn{2}{|c|}{ Variable } & How selected & Code & Code description \\
\hline \multirow{4}{*}{\multicolumn{2}{|c|}{ 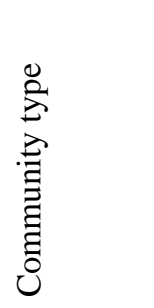 }} & \multirow{4}{*}{$\begin{array}{l}\text { Purposively, selected with } \\
\text { the help of district level } \\
\text { key informants; most from } \\
\text { the District Veterinary } \\
\text { Office (DVO) }\end{array}$} & 1 & Low productive potential, low market access \\
\hline & & & 2 & Low productive potential, high market access \\
\hline & & & 3 & High productive potential, low market access \\
\hline & & & 4 & High productive potential, high market access \\
\hline \multirow{3}{*}{\multicolumn{2}{|c|}{ 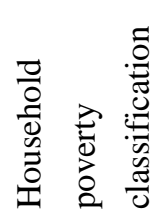 }} & \multirow{3}{*}{$\begin{array}{l}\text { Determined collectively by } \\
\text { the community members } \\
\text { during participatory wealth } \\
\text { ranking exercises }\end{array}$} & 1 & Non-poor \\
\hline & & & 2 & Poor \\
\hline & & & 3 & Ultra poor \\
\hline
\end{tabular}

In each selected community, a number of complementary quantitative and qualitative research techniques were used to collect the required data and information. These qualitative research techniques included, among other things, community mapping with cards, participatory scoring and ranking, and a set of carefully designed semi-structured questionnaires. The community participatory assessment process begun with a social mapping exercise to characterize the community's institutional, resource and asset context as well as to categorize the individual households based on their degree of vulnerability to food insecurity. Then within each food security stratum, focus groups were convened, each comprising a random sample of 8-10 individuals. In addition to being a powerful tool for collecting data that is enriched by purposeful use of interaction (Kitzinger 1996; McLafferty 2004; Merton et al. 1990; and Morgan 1996), focus group discussions (FGDs) also offer considerable advantage in terms of cost per informant. The number of participants per FGD was determined in conformity with recommendations of some sections of the literature. Krueger and Casey (2009), for example, suggests an optimal number of FGDs of 4-12 while Millward (1995) contends that data generated after about 10 FGDs are likely to be largely redundant.

The information gathered through these FGDs was complemented by community censuses, during which a very short questionnaire/listing form was administered to all the households represented at the community meeting, and a few in-depth household interviews using a semi-structured questionnaire. The in-depth household interviews were based on a sample 
drawn from a household sampling frame generated through the listing that took place during participatory community mapping. At that stage, data on basic characteristics of each household in the community were collected using a structured listing form. A total of 309 households were listed and interviewed across all the communities in the three districts. Using the listing information gathered, in each community, households were grouped into three strata - i.e. non-poor (NP), poor (P) or Ultra poor (UP). For operational purposes, a household was categorized as NP if it had enough to eat throughout the year, i.e. from harvest to harvest; as P if it normally had enough food to last from harvest up to Christmas but not between Christmas and the next harvest; and as UP if it had a longer period of food shortages, often experiencing severe food shortages even before Christmas. Care was taken to ensure representation of each of these food security strata in the household case studies to which a semi-structured questionnaire was administered. A total of 56 households interview were completed using the semi-structured questionnaire.

\subsection{Statistical Analysis}

The data were analysed using a wide range of techniques. These included post-interview brainstorming and collation of notes (for qualitative information), and quantitative analysis of rank/score data collected through the Participatory Rural Appraisal PRA exercises and factual information collected using pre-designed tables and semi-structured questionnaires. PRA is a planning approach focused on sharing and learning between local people, both urban and rural, and outsiders. It enables development managers and local people to assess and plan appropriate interventions collaboratively, often using visual techniques so that non-literate people can participate (World Bank, 2004). The quantitative analyses were accomplished using Microsoft Excel and the Statistical Package for Social Sciences (SPSS version 20.).

\section{Results and Discussion}

\subsection{Trends in Livestock Numbers}

In many respects, livestock ownership is an important determinant of vulnerability in Southern Province of Zambia. Figure 1 represents the trends in number of major livestock types as perceived by households in different poverty strata. Figure 1 also seems to confirm the assertation that larger livestock are owned more by the relatively non-poor households. The average number of cattle owned by non-poor households, for example, was 14 in 1996 as compared to 3 and 2 owned by poor and ultra poor households, respectively. Similar patterns can be observed with respect to goats (Figure 1b), poultry (Figure 1c) and other livestock types (Figure 1d). 

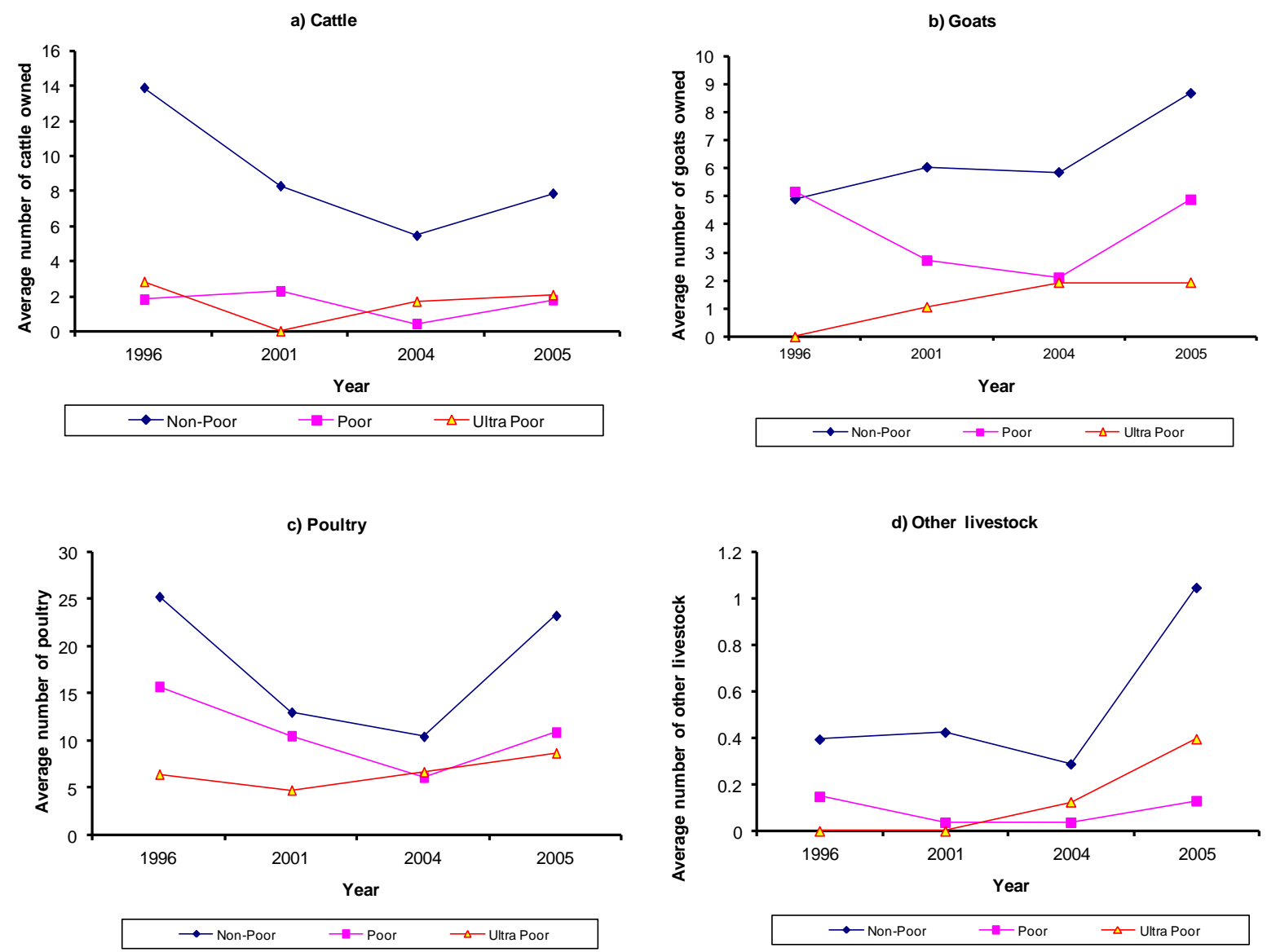

${ }^{a}$ Other livestock include sheep, pigs and donkeys

Figure 1. Trends in livestock ownership per household, disaggregated by poverty status

In terms of numbers, poultry are the most prevalent with an average household owning between 5 and 23. Livestock numbers reduced after 1996 due to emergencies such as disease outbreaks and drought. Recent studies have also shown that populations of cattle, goats, pigs and sheep have again declined between 2008 and 2012. Some of the reasons cited include low productivity, high mortality rates, disease outbreaks and poor pasture use among small-scale farmers (Lubungu and Mukuka 2012; ZDA 2011)

Table 2. Farmers' perceptions about the reasons that have caused declines in livestock numbers, 1996 through 2006

\begin{tabular}{|l|c|c|c|c|c|c|c|c|c|c|}
\hline & \multicolumn{3}{|c|}{ Sinazongwe } & \multicolumn{3}{c|}{ Namwala } & \multicolumn{3}{c|}{ Kazungula } \\
\hline $\begin{array}{l}\text { Reason for the decrease } \\
\text { in livestock numbers }\end{array}$ & Non-Poor & Poor & $\begin{array}{c}\text { Ultra } \\
\text { poor }\end{array}$ & Non-Poor & Poor & $\begin{array}{l}\text { Ultra } \\
\text { poor }\end{array}$ & Non-Poor & Poor & $\begin{array}{c}\text { Ultra } \\
\text { poor }\end{array}$ \\
\hline & $(1)$ & $(2)$ & $(3)$ & $(4)$ & $(5)$ & $(6)$ & $(7)$ & $(8)$ & $(9)$ \\
\hline
\end{tabular}




\begin{tabular}{|l|c|c|c|c|c|c|c|c|c|}
\hline $\begin{array}{l}\text { Sold to pay health } \\
\text { expenses }\end{array}$ & 0.00 & 0.15 & 0.30 & 0.14 & 0.17 & 0.00 & 0.08 & 0.18 & 0.33 \\
\hline $\begin{array}{l}\text { Sold to pay school } \\
\text { expenses }\end{array}$ & 0.21 & 0.15 & 0.20 & 0.24 & 0.30 & 0.00 & 0.33 & 0.18 & 0.33 \\
\hline Theft & 0.17 & 0.08 & 0.00 & 0.10 & 0.04 & 0.00 & 0.17 & 0.00 & 0.33 \\
\hline Dowry payment & 0.08 & 0.08 & 0.10 & 0.24 & 0.00 & 0.00 & 0.08 & 0.00 & 0.00 \\
\hline Home consumption & 0.17 & 0.00 & 0.10 & 0.24 & 0.13 & 0.00 & 0.25 & 0.09 & 0.00 \\
\hline Given to charity & 0.00 & 0.00 & 0.10 & 0.03 & 0.04 & 0.00 & 0.08 & 0.09 & 0.33 \\
\hline Wild animal attack & 0.04 & 0.00 & 0.00 & 0.07 & 0.00 & 0.00 & 0.08 & 0.09 & 0.00 \\
\hline
\end{tabular}

Table 2 represents the farmers' perceptions about the reasons that have caused declines in livestock numbers. Livestock diseases and distress selling (to raise money for food and school fees especially) were the most prevalent reasons cited by the communities. Similar reasons were also cited by Gandiwa (2012) in a study on livestock farmers in Zimbabwe who mentioned predation as a major cause, given proximity of the study area to a national park.

Diseases, are by far the most important reason, were most prevalently cited in Kazungula and Sinazongwe districts, affecting 67 percent and 50 percent of the ultra poor households, respectively (columns 3 and 9). Although, proportionately, Namwala does not face the problem of livestock diseases as much as the other two districts, in absolute terms the problem is also quite severe. There, though, the non-poor households, who tend to own large numbers of livestock, are the most affected (column 4).

In all the districts, the ultra poor have the added disadvantage of having limited knowledge of and access to veterinary services. However, the non-poor in Namwala also seem to easily get overwhelmed by disease outbreaks, given their large herds. Besides disease outbreaks and distress selling, other causes cited for declining livestock populations are largely trivial and important only among a few selected groups (Table 2). Whatever the causes are, that livestock populations are on the decline is not unique to Zambia but, rather, common to most other sub-Saharan African countries. This is contrary to trends observed in other parts of the world like Asia, where livestock numbers have surged owing to increases in incomes, economic growth, and demand for livestock products (Steinfeld et al., 2006). Since livestock ownership is often viewed as a symbol of wellbeing, it is not surprising that declining livestock numbers is associated with farmers sliding into the poor or ultra poor strata.

\subsection{Perceptions about the Impact of Livestock Losses}

Table 3 shows the perceptions of households of different poverty statuses about the impacts of livestock losses on their livelihoods. Five categories of impacts were identified: i) reduction in cultivated land area, ii) reduction in school-related expenditure, iii) sliding on the poverty ladder, iv) reduction in expenditure on household needs such as clothing, and v) several other minor impacts. These results are consistent with Suresh et al. (2010), who contended that degradation of common pasture had led to declining numbers of dairy cattle with similar welfare implications. For each of the perceived impacts, the figures in Table 3 are proportions of interviewed households that indicated having experienced the adverse effect in question. 


\section{Ml Macrothink}

Table 3. Households' perceptions about the impacts of livestock losses

\begin{tabular}{|c|c|c|c|c|c|c|}
\hline \multirow{2}{*}{\multicolumn{2}{|c|}{$\begin{array}{l}\text { Household food security category } \\
\text { by district }\end{array}$}} & \multicolumn{5}{|c|}{ Perceived impact } \\
\hline & & $\begin{array}{c}\begin{array}{c}\text { Reduced } \\
\text { cultivated } \\
\text { land area }\end{array} \\
(1) \\
\end{array}$ & $\begin{array}{c}\begin{array}{c}\text { Reduced } \\
\text { school-related } \\
\text { expenditure }\end{array} \\
(2) \\
\end{array}$ & $\begin{array}{c}\begin{array}{c}\text { Have } \\
\text { become } \\
\text { more food } \\
\text { insecure }\end{array} \\
(3)\end{array}$ & $\begin{array}{c}\text { Reduced } \\
\text { expenditure } \\
\text { on clothes } \\
(4)\end{array}$ & $\begin{array}{c}\begin{array}{c}\text { Other }^{\mathrm{a}} \\
\text { Impacts }\end{array} \\
(5)\end{array}$ \\
\hline & & ------------ & --- Proportion & interviewec & ouseholds ----- & ------------ \\
\hline \multirow{3}{*}{ 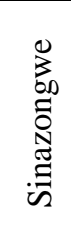 } & Non-Poor & 0.12 & 0.16 & 0.18 & 0.10 & 0.08 \\
\hline & Poor & 0.17 & 0.14 & 0.11 & 0.06 & 0.11 \\
\hline & Ultra Poor & 0.07 & 0.07 & 0.05 & 0.07 & 0.02 \\
\hline & & & & & & \\
\hline \multirow{3}{*}{ 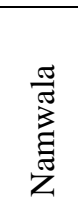 } & Non-Poor & 0.08 & 0.17 & 0.17 & 0.11 & 0.03 \\
\hline & Poor & 0.09 & 0.09 & 0.14 & 0.09 & 0.04 \\
\hline & Ultra Poor & 0.14 & 0.14 & 0.14 & 0.23 & 0.09 \\
\hline & & & & & & \\
\hline \multirow{3}{*}{ 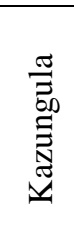 } & Non-Poor & 0.12 & 0.17 & 0.24 & 0.24 & 0.12 \\
\hline & Poor & 0.14 & 0.06 & 0.20 & 0.17 & 0.11 \\
\hline & Ultra Poor & 0.11 & 0.06 & 0.26 & 0.14 & 0.09 \\
\hline
\end{tabular}

aOther impacts (e.g. less income for health expenses, no friends, lack of transport, no easy way of banking, less income for dowry payment, no manure and less funeral support).

Kazungula farmers seem to have been the most affected, with at least 20\%indicating that they had slid on the poverty scale (column 3). Between 14 and $24 \%$ have reduced their expenditure on clothes. Also more than a $10^{\text {th }}$ of the farmers indicated having reduced their cultivated land area as a result of declining livestock numbers. While in Kazungula the households were affected almost equally, in the other two districts, it is the non-poor and the poor that seem to be most affected. This makes sense since these categories of households tend to be more dependent on livestock than the ultra poor households.

The non-poor households in Namwala, however, were less affected as they tend to own many herds of cattle, and have reliable income sources with other means of having their fields cultivated. On the contrary, the ultra poor in Sinazongwe were the least affected by livestock losses. This is consistent with the fact that Sinazongwe's ultra poor tend to rely more on such livelihood activities as field crop production, gardening, and piece work and much less on livestock rearing. Two other reasons make Sinazongwe relatively more resilient to livestock-related risks. First, the district's livestock sector is much more diversified than the other two districts. Second, Sinazongwe has got the largest populations of goats, which are 
genetically much more resilient to climate related shocks than other types of livestock.

Comparatively, Kazungula is the most vulnerable of the three districts to livestock-related shocks. Because of high dependency on livestock among the well off in this district, these shocks also tend to affect this category of households the most. Namwala is in between the other two districts as far as households' vulnerability to livestock-related shocks is concerns.

\section{Summary and Conclusions}

Our study used data generated from a mixed-methods survey to elicit smallholder farmer's perceptions about trends in livestock numbers and their impacts on livelihoods. Qualitative research techniques involving the use of community mapping with cards, and participatory scoring and ranking together with semi-structured questionnaires were administered in the communities and households of Kazungula, Namwala and Sinazongwe Districts. The results indicate that disease outbreaks and distress selling of livestock in times of droughts have generally led to declining livestock numbers in all the three districts. As a result there has been a myriad of impacts, including: reduced cultivated land area, reduced school-related expenditure, sliding of households on the poverty scale and reduction of expenditure on other household needs such as clothing.

With a more productive livestock enterprise, it seems possible for the households to improve their food security standing. However, poor management and failure to anticipate and prepare for livestock-related shocks could have devastating effects, demonstrated by households dropping down the ladder from very comfortable welfare positions to ultra poor positions. The effects were especially severe in Kazungula District, followed by Namwala. The diversity of livestock species and the high concentration of the more resilient goats have made Sinazongwe District communities relatively more resilient to livestock-related shocks. All these point to not only the need for enhanced knowledge about livestock husbandry in the communities, but also the need to pay attention to the inherent diversity in the characteristics of both the households and the livestock systems across the districts.

\section{Acknowledgements}

This study is in a part, based on work done by the authors for the International Livestock Research Institute (ILRI) and the Food and Agriculture Organization of the United Nations (FAO). However, the views expressed in this paper do not necessarily represent the official positions of ILRI and/or FAO. All errors in interpretation are the authors' own. Jairos Sambo also provided invaluable research assistance support during the final stages of the manuscript.

\section{References}

Delgado, C, R. Mark, S. Henning, S. Ehui, \& C. Courbois. (1999). Livestock to 2020: The Next Food Revolution. Food, Agriculture, and the Environment. Discussion Paper No. 28. Washington, D.C.: International Food Policy Research Institute.

FAOSTAT.(2006). Livestock Impacts on the Environment. Agricultural and Consumer Protection Department. Rome, Italy. 


\section{I Macrothink}

Journal of Agricultural Studies

ISSN 2166-0379

2014, Vol. 2, No. 2

Gandiwa, E. (2012). LocalKnowledge and Perceptions of Animal Population Abundances by Communities adjacent to Northern GonarezhouNational Park, Zimbabwe.Tropical Conservation Science. 5(3), 255-269.

GRZ. (2005b). Annual Report. Department of Agriculture.Ministry of Agriculture and Cooperatives (MACO). Sinazongwe District, Zambia.

GRZ. (2006). First Quarter Report. Department of Agriculture, MACO, Kazungula District, Zambia.

GRZ.(2005a). Annual Report.Department of Agriculture.Ministry of Agriculture and Cooperatives (MACO).Namwala District, Zambia.

IFAD. (2009). Livestock and Climate Change. Livestock Thematic Papers: Ttools for Project Design. Rome. Italy.

Lubungu, M. Mukuka,R. M. (2012). The status of smallholder livestock sector in Zambia. Paper Presented to the Parliamentary Committee on Agriculture. Government of Republic of Zambia, Lusaka, Zambia.

Rola, A. Rola, W. Tiongco, M., \& Delgado, C. (2003). Livestock Intensification and Smallholders: A Rapid Reconnaissance of the Philippines Hog and Poultry Sectors. Discussion paper No. 59.

Sherpa, Y. D., \& Kayastha, R. B. (2009). A study of Livestock Management Patterns in Sagarmatha National Park, Khumbu Region: Trends as affected by Socio-Economic Factors and Climate Change. Journal of Science, Engineering and Technology. 5(2): 110-120.

Steinfeld, H. Wassenaar, T., \& Jutzi, S. (2006). Livestock Production Systems in Developing Countries: Status, Drivers, Trends. Rev. Sci. tech. Off. Epiz. 25(2), 505-516.

Suresh, A. Gupta, D. C., \& Mann, J. S. (2010). Degradation of Common Pastures: An Economic Perspective of its Impact on Livestock Farming Strategies. Agricultural Economics Research Review, 23, 47-56.

Thornton, K. P (2010). Livestock production trends: recent trends, future prospects. Food Agricultural Organization. Rome, Italy.

World Bank. (2004). Monitoring and Evaluation: Some Tools, Methods and Approaches. Washington, D.C, USA.

ZDA. (2011). Agriculture, Livestock and Fisheries: Sector Profile. Zambia Development Agency, Government of the Republic of Zambia, Lusaka, Zambia.

\section{Copyright Disclaimer}

Copyright reserved by the author(s).

This article is an open-access article distributed under the terms and conditions of the Creative Commons Attribution license (http://creativecommons.org/licenses/by/3.0/). 